The results were analyzed according to indices of developing a burning disease, cytological examination, lipid peroxidation study and antioxidant defense (vitamin "E", ceruloplasmin), pro-inflammatory interleukins (IL-1 $\beta$, IL-6, IL-8, TNF- $\alpha$ ), ) on the first and 10-th day of therapy. The degree of differences was considered to be significant when $p<0,05$.

Results: Due to more active processes developing in the wound earlier terms of forming marginal ( $7,6 \pm 1,6$ days) and complete epithelization of wounds $(28,2 \pm 3,3$ days), scarring $(31,3 \pm 2,4$ days) $(p<0,05)$ were determined for certain in patients of the main group in comparison with patients of the control group $(10,7 \pm 1,4$ days, $20,9 \pm 3,8$ days, $29,9 \pm 2,3$ days, $39,7 \pm 3,2$ days accordingly). Duration of the temperature reaction is $11,9 \pm 0,6$ days and that of the painful syndrome in the main group made up 13,4 $\pm 0,7$ days. These indices in the control group made up 16,6 \pm 0,7 days and $19,9 \pm 1,5$ days accordingly $(p<0,05)$.

Cellular composition of the wounds on the first day of therapy did not significantly differ in patients of both groups. In the 21-st day of therapy regenerative and regenerative - inflammatory types of cytograms were determined in patients of the main group while inflammatory and regenerative type of cytograms remained in patients of the control group.

Patients with superficial burns in both groups had excessive and lingering hyperproduction of pro-inflammatory interleukins (IL-1 $\beta$, IL-6, IL-8, TNF- $\alpha$ ). Application of the proposed method furthered the decrease of their level and acceleration of reparation processes. By the 10-th day of therapy in patients of the main group having burning wounds the level of IL-1 $\beta$ content in the serum decreased by $45,5 \%$ ( from $132,9[21,5 ; 302]$ to $72,4[8,7 ; 127,6]$ ), IL-6 - 40\% (from 112,5 [51,4; 216,7] to67,5 [13,9; 120,8], IL-8 - 49,3\% (from 230,4 [123,8; 328,5] to $116,7[69,8 ; 254,6]$ ) and TNF- $\alpha-62,8 \%$ (from $43,2[15,04 ; 67]$ to $16,07[6,7 ; 45,8]$ ), and in the control group only $-18,3 \%, 2,9 \%, 3,6 \%, 6,5 \%$, accordingly.

At the beginning of therapy there were not significant differences in indices of lipid peroxidation and AOD in patients of both groups. M.u. indices decreased by $46,8 \%$ and r.c. indices - by $47,9 \%$ in patients of the main group by the tenth day of treatment while m.u. indices decreased by $20,4 \%$ and r.c. indices - by $31,7 \%$ in patients of the control group. The content of AOD components increased significantly in the main group than in the control one. In patients of the main group the content of vitamin "E" increased by $39,1 \%$ and that of ceruloplasmin - by $35,4 \%$ and in the control group - by $8,7 \%$ and - by $3,6 \%$ accordingly.

Conclusion. Application of HBO and antioxidant therapy with dihydroquercetin (Lavitol cosmetic", BAA "Lavitol - B").) activates the process developing in the wound that allows to improve the results of treatment of patients with superficial burns.

\title{
REFERENCES
}

1. Karyakin N.N. Technologies of burns treatment in the conditions of humidity // International journal of applied and fundamental investigations .2015. № 9 (part 3). P. 495-499.

2. Bagaev V.G., Sergeeva V.V., Bobrova A.A. etc. Hyperbaric oxygenation in the complex therapy of wounds in children // Wounds and wound infections. 2014. V.1, № 2. P. 31-37.

3. Lutsevich O.E., Tamrazova O.V., Shikunova A.U. etc. Modern view on pathology and treatment of purulent wounds // Surgery. 2011. № 5. P. 72-77.

4. Lavitol cosmetic. URL: https://www.ametis.ru/production/lavitol-cosmetics (date of address 15.07.2017).

AUTHORS: Olifirova Olga Stepanovna - Doc. Med. Sc., Head of the department of surgical diseases FRAE, tel. 89145544652, mail: olif.oc@mail.ru Kozka Aleksandra Aleksandrovna - post-graduate of the department of surgical diseases FRAE, tel.89638488407, mail: kozka.a.89@mail.ru Volosenkova Elena Alekseevna - assistant of the department of foreign languages

UDC 616.24-001-616.248 DOI 10.22448/AMJ.2017.3.141-142

\section{FEATURES OF BRONCHIAL ASTHMA CLINICAL COURSE IN CONJUNCTION WITH BRONCHIECTASIS}

\author{
Prikhodko O.B., Kostrova I.V., Pogrebnaya M.V., Goryacheva S.A., Smorodina E.I.
}

\author{
Amur state medical academy, Blagoveshchensk, Russian Federation
}

\begin{abstract}
International data indicate an increase in the prevalence of bronchiectasis in recent years. In connection with the expansion of computer diagnostics abilities and an increase in the detectability of bronchiectasis in various diseases, interest in this problem has greatly increased. Presenting a clinical case of comorbid patient observation with the presence of steroid-dependent bronchial asthma and COPD, the so-called cross-over syndrome, in combination with cystic hypoplasia and bronchiectasis.
\end{abstract}

Key words: bronchiectasis, bronchial obstruction, bronchial asthma

International data are showing an increase in the prevalence of bronchiectasis in recent years. Bronchoectasis (BE) among other lung diseases are taking part from $10 \%$ to $30 \%$. With fluorography of chest organs, it's detected in 1-2 of 1000 people, and in the survey with the use of bronchography - in $0.5 \%$ of the population. According to pathoanatomical studies, bronchiectasis occurs in $2-4 \%$ of the adult population. Bronchiectasis in $2 / 3$ of the patients was noted before the age of 20 years. At the age of 10 years, bronchiectasis is equally common in boys and girls, but among adults, men suffer more often than women 1.5-3.0 times [1,2,3].

Material and methods. In connection with the expansion of the possibilities of computer diagnostics (use of high-resolution and spiral computed tomography) and an increase in the detectability of bronchiectasis in various diseases, interest in this problem has visibly increased. In Europe F.C. Ringshausen et al. reported an increase in the number of 
hospitalizations of persons with BE in Germany between 2005 and 2011, adjusted for age by 2.9\% per year. Similar data were recorded in the US: general prevalence of BE is unknown exactly, by the recent estimates - 51 cases per 100,000 people, most likely underestimated. In a recent multicenter European study involving 1310 patients with EB, the frequency of exacerbations was estimated to be 1.8-3.0 in 1 patient per year, with a follow-up hospitalization rate of 26.6$31.4 \%$ for 2 years of follow-up. In Russian Federation, there is no precise data on prevalence of BE. However, due to the improvement in lung imaging technology, the prevalence of BE should be revised. In the pathogenesis of BE, great importance is attached to two main factors - the local inflammatory (suppuration) process in the bronchi (local purulent endobronchitis) and obstructive atelectasis. Obturation bronchus and bronchial secretions delay excretion contribute to the development and progression of inflammation (suppurative) process in a bronchus lumen distal to the obstruction.

The pathophysiological mechanism of development of BE is most correctly understood in terms of the hypothesis of the "vicious circle": progression of the disease is associated with insufficient evacuation of sputum in the airways, bacterial colonization, inflammation of the respiratory tract and their structural damage. Therefore, the goal of therapy should be to stop or reverse these processes and thereby to "break the vicious circle".

The clinical observation of the patient S., 44 years old, who entered the pulmonology department of the Amur Regional Clinical Hospital with complaints of asthma attacks up to 6-8 times a day, including those that are nightly, dabbled with berodual, dyspnea at rest, cough with difficult to separate mucopurulent sputum, temperature raising to $37.8^{\circ} \mathrm{C}$. From anamnesis it is known that asthma attacks disturbing from 17 years of age, acute - up to 3-4 times a year, mainly in spring - autumn period. Allergic history burdened: polyvalent sensitization (household, pollen, food). In 2002 suffered bilateral pneumonia. Since 2005 he's taking systemic glucocorticoids (prednisolone) in a constant maintenance dose of $10 \mathrm{mg}$ per day, Symbicort, Berodual. Twice in the anamnesis (in 2010 and 2011) - life-threatening exacerbation of asthma, was hospitalized in the intensive care department.

The state of moderate severity, the auxiliary musculature participates in the act of breathing. Chest of emphysematous form, breathing weakened, dry wheezing wheezes on exhalation, BR - 28 per minute. The heart sounds are muffled, rhythmic, the accent of 2 tones on the pulmonary artery. According to CT of chest organs: cystic hypoplasia and bronchiectasis in the lower lobes of both lungs, the internal diameter of the bronchi is greater than the neighboring arteries, there is no typical form of bronchi (the same diameter as the parental branch> $2 \mathrm{~cm}$ ), the walls of the bronchi are thickened, thin-walled cystic formations, with horizontal levels of fluid levels. The conclusion of fibrobronchoscopy: signs of diffuse endobronchitis, intensity of inflammation III, hyperreactivity of bronchi II, a positive Sul sign. Subsequently, sanative bronchoscopies were performed. In the sprouting on microflora: pneumococcus $\mathrm{x} 106$, hemophilic rod x105, sensitive to amoxiclav, cefriaxone, levofloxacin.

Clinical diagnosis: Bronchial asthma, mixed form (atopic, infectious-dependent), severe uncontrolled course, steroid-dependent variant, exacerbation. COPD, mixed type, severe course, exacerbation. Cystic hypoplasia and bronchiectasis of the lower lobes of both lungs. $\mathrm{CPH}$, compensation stage. RI-II. Conclusions. This clinical case is interesting for the patient's comorbid state - the presence of steroid-dependent BA and COPD - the so-called cross-over syndrome - in combination with cystic hypoplasia and bronchiectasis, which dictates the need for a personified approach to choosing the amount of therapy to achieve asthma control and prevention of exacerbations.

\section{References}

1. Grigoriev E.G. Chronic festering lung diseases // Bulletin of the East Siberian Scientific Center of the Siberian Branch of the Russian Academy of Medical Sciences. 2014. № 4 (98). P.100-104.

2. Zarembo I.A., Kiseleva E.A., Zarayskaya L.S. and others. Bronchoectatic disease: a modern view of the problem // Practical pulmonology. 2015. № 4. P. 27-33.

3. Shoikhet J.N., Titova E.A., Dukov L.G. and others. Clinical course and antibacterial therapy of chronic obstructive pulmonary disease in combination with bronchiectasis // Siberian Medical Journal. 2013. T.28, №4. P.67-70.

UDC 616.34: 616.12-008 DOI 10.22448/AMJ.2017.3.142-143

\section{PECULIARITIES OF HEART RHYTHM DISTURBANCE IN CHILDREN WITH PATHOLOGY OF THE GASTROINTESTINAL TRACT}

\section{O.V. Shanova, E.F. Filonenko}

\section{Amur State Medical Academy, Blagoveshchensk, Russia}

Abstract: This article is devoted to the problem of arrhythmias in children with gastrointestinal pathology and their correlation with vegetative nervous system. A comparative assessment of arrhythmias in children with gastrointestinal pathology and without it. Children and adolescents with with gastrointestinal pathology have more wide range of cardiac arrhythmias and conduction failure. There is a group of changes associated with peculiarities of autonomic regulation (bradycardia, rhythm migration). These peculiarities require an integrated approach to the treatment of such patients with the use of vegetotrophic drugs.

Key words: children, gastrointestinal tract, heart rhythm disturbance.

Chronic pathology of the digestive tract in children is one of the topical problems of modern medicine. Extremely wide prevalence of the pathology of the gastroduodenal zone, the incidence of gastrointestinal tract (GI) diseases to the prolonged, recurrent course of frequent development of complications, a decrease in the quality of life of patients, economic losses pose the problem of fighting chronic gastroduodenal pathology in the category of so142 Амурский медицинский журнал №3 (19) 2017 